\title{
SCHEDULE OPTIMIZATION OF A LARGE HOSPITAL PROJECT - 4D BIM STARTING WITH THE DEMOLITION
}

\author{
Ivanka Iordanova ${ }^{1}$, Fernando Valdivieso ${ }^{2}$, Carolyne Filion ${ }^{3}$, and Daniel Forgues ${ }^{4}$
}

\begin{abstract}
There are multiple studies emphasising the positive interaction between Lean Construction and BIM use. Nevertheless, it is often difficult to find a direct link between this integrated strategy and the project outcome. This paper presents a case study of a large hospital project in a dense downtown environment, where BIM and Lean were used in synergy - mutually informing each other and catalysing their impact. This project created opportunities for multiple innovations and optimisations. This paper will focus on the positive impact from simultaneously applying 4D-BIM and a variation of takt-time planning to the demolition of the old hospital building adjacent to the new one. The optimization between the demolition and the new construction was crucial for the project, as it allowed the Design-Builder's company to shorten the schedule by two months and to win the contract. Another innovation was the automated update between master schedule, takt-time plan, BIM model, and project documents (including 2D plans and Virtual Reality). This automated loop makes the schedule available to each construction stakeholder (from client and designers, to the foremen) in the format that is most appropriate and useful for them. It also allows for easy progress tracking and control.
\end{abstract}

\section{KEYWORDS}

Lean Construction, 4D BIM, Mega-Hospital Project, Schedule Optimization, Demolition

\section{INTRODUCTION}

The construction industry is notorious for its low productivity and resistance to change. According to a recent report of the World Economic Forum, the overall productivity in the sector has remained nearly flat for the last 50 years. Projects are much more complex and technology intensive than before, while the fragmentation of the industry and the traditionally adversarial contractual framework do not favour collaboration.

In this context, Building Information Modelling (BIM) plays an important role in productivity and performance optimization, as it is the key enabler of and facilitator for many other technologies (World Economic Forum 2016). On the other hand, general

1 Professor, Département de Génie de la Construction, École de Technologie Supérieure (ETS), Montréal, Canada, ivanka.iordanova@etsmtl.ca, orcid.org/0000-0002-4596-2604

2 Innovation Manager-APEX \& Civil Operations, Pomerleau Inc., 500 St-Jacques, Montréal, Canada, fernando.valdivieso@pomerleau.ca, orcid.org/0000-0001-9741-8419

3 Innovation Manager - R\&D and Special Projects, Pomerleau Inc., 500 St-Jacques, Montréal, Canada, carolyne.filion@pomerleau.ca, orcid.org/0000-0003-2559-504X

4 Professor, Département de Génie de la Construction, École de Technologie Supérieure (ETS), Montréal, Canada, daniel.forgues@etsmtl.ca, orcid.org/0000-0002-1790-671X 
productivity improvements, like the use of 'lean' principles and methods can optimize existing processes, and reduce completion times by $30 \%$ and cut costs by $15 \%$ (The Boston Consulting Group 2018).

This paper will present the theoretical foundations and the digital implementation of a 4D-BIM artefact based on lean planning strategies. It was used to optimize the deconstruction and demolition processes, and, as a consequence, yielded a significant shortening of the project timeline.

\section{LITERATURE REVIEW}

The intensification and the generalization of the adoption of BIM during the last 15 years has given a significant push to the implementation of Lean principles during construction projects. The BIM practitioners quickly started recognizing the Lean strategies as underlying processes for various BIM uses implementation. Thus, Lean Construction workshops and certification credits are often part of BIM conferences. The opposite was not so true, though - Lean Construction practitioners much more seldom were considering BIM as a Lean-enabling platform, even if the scientific literature had started reporting Lean and BIM interactions and systemizing them (Sacks et al. 2010a, Sacks et al. 2010b).

\section{ON BIM AND LEAN INTERACTION}

The interactions between Lean and BIM were systemized by Sacks et al. (2010a) in a matrix, based on case studies in which the authors evaluated the relations between 24 Lean Construction principles and 18 BIM functionalities. The interactions are represented in a table and illustrated by examples taken from the case studies. Fifty positive interactions are found, where BIM and Lean are mutually reinforcing each other. Several negative interactions are identified, mainly where the ease of generation of digital alternatives may provoke more time-consuming post-processing. A recent publication gives detailed examples of improving construction through the combined use of Lean and BIM (Sacks 2018).

Elmaraghy et al. (2018) extends the BIM and Lean interaction table making it applicable for deconstruction and they find synergies between the BIM functionality of rapid simulation and evaluation of deconstruction alternatives, which allows for early planning and transparent decision making concerning the means and methods, among many other positive interactions. The objective of that paper is waste reduction during deconstruction, so the authors do not specifically explore the optimisation of the schedule. In the extended interaction matrix, they find synergy with the reduced cycle time, but not with reduced variability.

\section{ON BIM FOR DECONSTRUCTION AND DEMOLITION}

Scientific literature reports on various works towards effective deconstruction and demolition processes. 4D-BIM is proposed for visualisation of the deconstruction scheduling (Ge et al. 2017). BIM-based deconstruction plug-ins are developed to facilitate the process (Akbarnezhad et al. 2014).

Some authors have created a framework allowing to take into account the effectiveness of deconstruction from the very beginning of the design (Akinade et al. 2017). They propose guidelines for effective BIM-based Design for Deconstruction.

Most of the research on deconstruction focuses on minimizing the waste during this process (Elmaraghy et al. 2018). For example, Schultmann and Rentz (2002) explore 
deconstruction scheduling and find that time and cost for deconstruction can be reduced by more than $50 \%$, and the recycling quotas of more than $90 \%$.

No publications specifically address integrated 4D-BIM construction simulation of deconstruction of the existent and construction of the new building.

\section{On Production System ANd SCHEduling}

Lean construction is especially performant for production system design and control. Multiple concepts and scheduling strategies have been developed and their impact on the project has been researched through the years. Thus, work structuring has been defined by Ballard as "the development of operation and process design in alignment with product design, the structure of supply chains, the allocation of resources, and design-forassembly efforts" (Ballard 2000). Location-based methodologies have also a long history as framework for production management, where location is defined as the unit of analysis for production and provide the container for all project data and it is also the primary work division. Meanwhile, task is considered the method of control that contains the data related to production of the project. Location-based systems focus on the control of resources moving through the building doing physical work. This resource control results in an effective way to stabilize the flow and to reduce the variability of the cycle time. Location in a location-based methodology is divided hierarchically by the Location breakdown structure (LBS) (Kenley and Seppänen 2009).

Another important concept, the takt-time represents the unit of time within which a product must be produced in order to match the rate at which that product is needed. In construction, it is applied to a physical location and needs to match the rate at which a given location has to be liberated for the next construction task. It stabilises the flow for the scheduling activities and the Last Planner ${ }^{\circledR}$ System (Frandson et al. 2014).

Using takt-time, and quantities automatically extracted from a BIM model (mainly the structural system), Melzner (2019) proposes and tests a semi-automatic 4D simulation creation. According to the author, one of the limitations of his system is the need for comprehensive knowledge of the construction processes and its subsequent activities. Even more, this system cannot be used by a General Contractor because he does not have access to the production rates of the trades (especially in our regional context).

Line of balance is another representation which results in better visualization for the link between the flow of work of the different crews (Bernardes 2003). The "all activities critical planning" (ACP) method, a graphic representation largely used in Peru since the 1990's, is considered a variation of the line of balance scheduling (Ghio et al. 1997). Due to the graphical similarities, this study considers it a variation of the takt-time planning representation.

\section{METHODOLOGY}

This paper presents a case study in which an artefact (one of the outcomes of the Design Science Research) was created and evaluated. We would like to focus more on this second aspect - the digital artefact, as it has the potential to be reused in further projects. A combination of case study and Design Science Research provides methodological basis for this study. Design science is a research paradigm in which a designer answers questions relevant to domain problems via the creation of innovative artefacts, thereby contributing new knowledge to the body of scientific evidence (Hevner and Chatterjee 2010). In the presented case, a combination of BIM-4D and Lean strategies are used in an innovative way, to optimize the overall timeline of the project. The developed digital 
artefact was applied to a mega-hospital project and the evaluation was positive, resulting in winning of the project bid.

\section{DOCUMENT STRUCTURE}

The paper will first present the context of the project and the practical problem that had to be solved. Then, we'll address the process of creation of the digital artefact, and finally the method of its validation.

\section{THE PROJECT}

\section{CONTEXT OF THE STUDY}

This research took place during the preconstruction and the construction phases of a mega-hospital project. The new buildings (two above-ground blocks of around 17 storeys, and 8 floors of underground parking garage) represent the second phase of a large hospital complex in a dense urban area. The new development is erected around and on the place of an existing big hospital, which had to be demolished for the above-mentioned new constructions to take place. The contractual mode was a Public-Private-Partnership, assuring a relatively good collaboration environment for the design-builder's team. The hospital buildings constructed during the Phase-1 (including the emergency) remain fully operational, and have to be non-disturbed.

\section{Practical Problem}

During the bidding stage, the design-builder's team needed to significantly shorten the construction schedule in order to meet the Client's requirements. Given the complexity of the project and the large amount of risk associated with a potential non-compliance to the terms of the contract, the project team was looking for a reliable way to generate alternatives, and to objectively evaluate them.

Given the rich Virtual Design \& Construction (VDC) experience of the company, it was natural to use BIM modelling, simulations and high level of coordination and collaboration throughout the project in order to reduce the risk to the maximum, and to deliver best possible value to the client.

Based on Lean Construction strategies, all projected buildings were modelled following the Location-based structure (Figure 1). The existent buildings from the first phase of the project were also modelled so that the multiple connection points can be precisely executed.

Despite the various optimizations of the schedule, the timeline was still too long and not satisfactory for the client. The BIM/VDC team (named with the two abbreviations because of cultural and regional circumstances) was looking for a way to explore more alternatives. The planning and scheduling tools they had at hand - Primavera, MS Project, BIM model, and even the 4D simulations were not providing the necessary integration to study the different scenarios and to take an informed decision with a reasonable risk level for the outcome of the project.

\section{PRODUCTION SYSTEM DESIGN}

The BIM/VDC team needed to structure a new production system design for the project, which can fit with the particularities of the French Canadian construction industry (Tahrani et al. 2015) and can integrate BIM and other technologies in the most efficient way to add value for the project. 
Based on Ballard (2000), we introduced the use of location as a fundamental unit to structure the construction operations and the project design. At the same time, location in a building could be analysed as a topological space in the three-dimensional Euclidean space of BIM tools (Paul and Borrmann 2009). This Euclidean space used in BIM models can be divided by a location breakdown structure (LBS) by discipline (Architecture, Structure, MEP, etc.). Therefore, each modelled object of a building can be associated to an LBS. This association grants the possibility to use a location as a hierarchical division, as well as a new information parameter inside each digital object (as shown on Figure 1).
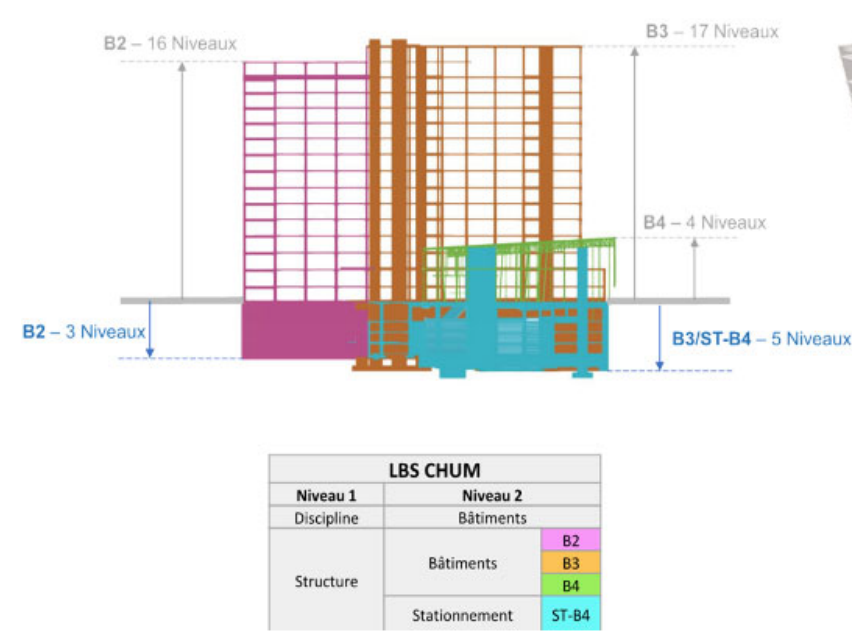

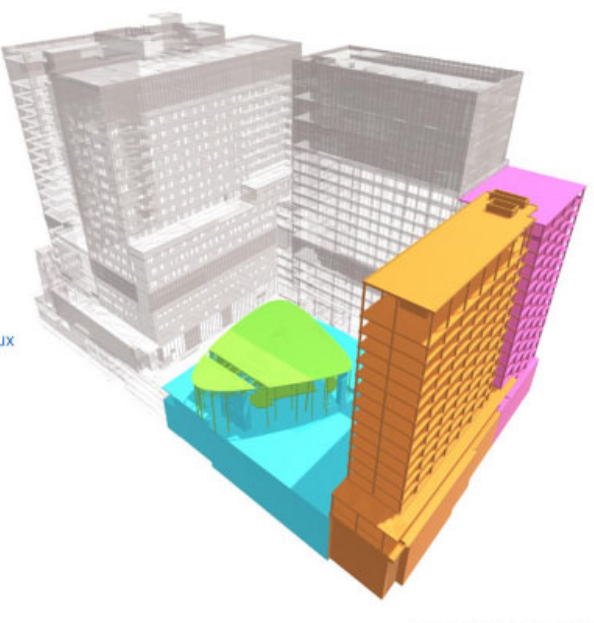

$-\cdots \cdot-\cdot-\cdots$

Figure 1: Modeling, LBS structure, and visual communication through colour-coding of the new hospital project

When the location is assigned as a parameter in a BIM database, it becomes the unifying code through the whole information flow. Thus, the present case study, the location becomes a virtual key that enables the link between digital databases such as cost systems, planning and scheduling systems, document management systems, quality control systems, facility management systems and BIM systems.

\section{CHOICE OF PLANNING AND SCHEDULING METHODOLOGY}

As location was our work structuring foundation, we decided to use location-based planning and scheduling. However, the choice was not easy because the graphic representation of flowline or line of balance was quickly rejected by the field team. The Last Planner ${ }^{\circledR}$ System (Ballard 2000) having had bad publicity in the past, the use of post-its was rejected. However, in a previous project, the team had introduced the ACP graphical representation (Ghio et al. 1997), which was quickly accepted by the field team.

The predominant use of CPM scheduling trough Software platforms like Primavera (P6) or MS Project has conditioned the way to communicate to the field the common information contained in every schedule such as time, location and description of the task. We observed in several projects the lack of comprehension of the 3 weeks look ahead schedule (3WLAS), shared as an extraction of the CPM schedule as well as hard copy or pdf file. Most of the subcontractor's foremen and superintendents use these 3WLAS to know only the timeframe for their tasks (start date and finish date). To facilitate the communication, we proposed the use of production control charts. It is a location-based 
tool designed to show the status of the project on one or very few pages (Kenley and Seppänen 2010).

\section{DESIGN AND CONSTRUCTION PROCESS OF THE ARTEFACT}

The method reported by Iordanova et al. (2019) served as a basis for the new development. The artefact was constructed following an iterative and collaborative processes involving the VDC planners, the superintendents, the project manager and the foremen of several specialized trades. The created artefact was then used by the same actors, and also by the project director and the client, to make informed decision for project's timeline optimization. The artefact's construction process consisted of several phases integrating BIM, LBS, takt-time planning, 4D simulations and integrated design of the deconstruction and excavation activities.

\section{LBS-based modelling of the deconstruction and demolition}

During this phase, the existent buildings which had to be deconstructed and demolished, were modelled with a lot of detail - including the interior parts. The types of activities as well as the risk level were colour-coded and presented both in the schedule (MS Project) and on the model (Figure 2).

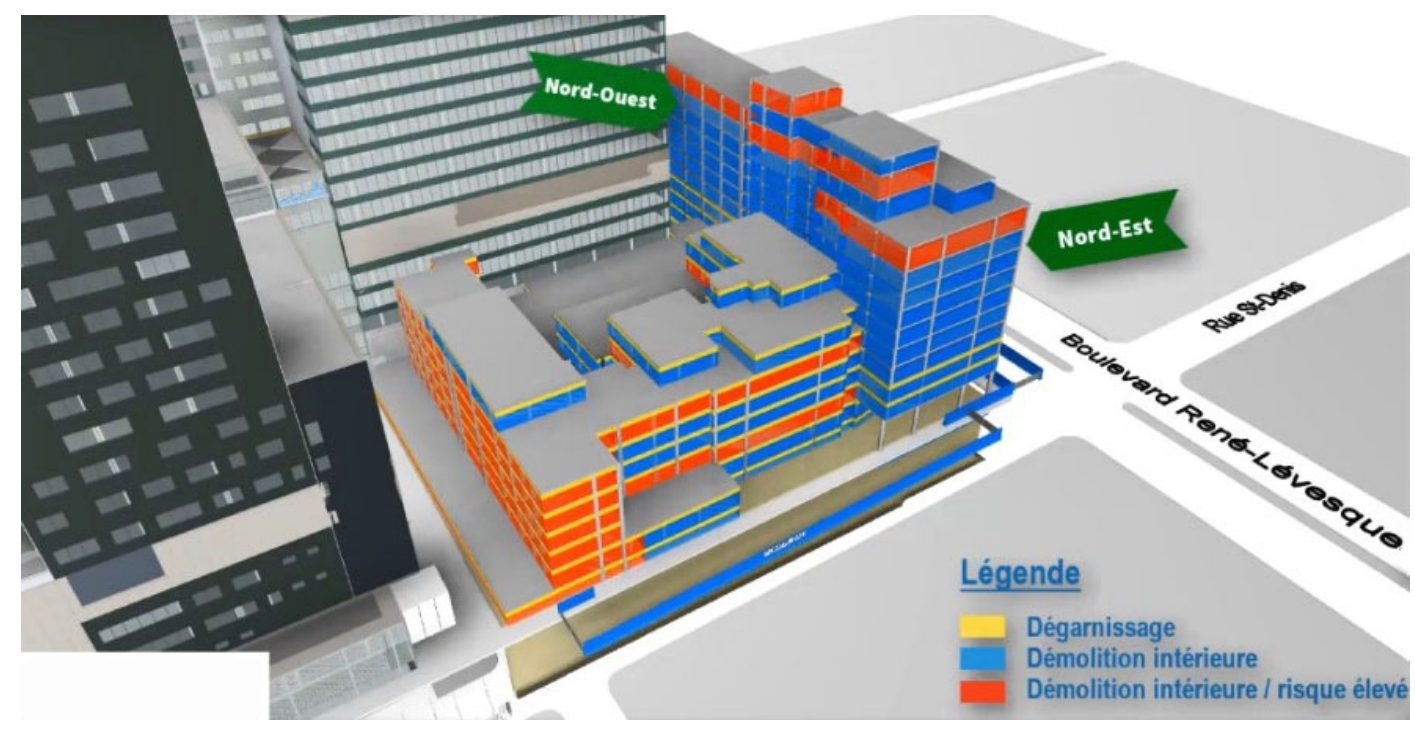

Figure 2: Modeling and color-coding of the types of demolition of the existing hospital complex: deconstruction, interior demolition, exterior demolition (high risk)

\section{Takt-time Planning}

As mentioned in the literature review, takt-time planning is a powerful Lean strategy for flow stabilization. It also provides potential for schedule optimization. The BIM/VDC planners together with the superintendent created a takt-time plan for the deconstruction of the 3 buildings, taking into account the constraints of the sub-trades, their daily productivity rate, and the contractual context.

In parallel with this, takt-time plan of the excavation, the construction of the retaining wall and of the new construction were prepared together with the respective specialized trades in view of the whole project process (Figure 3). 

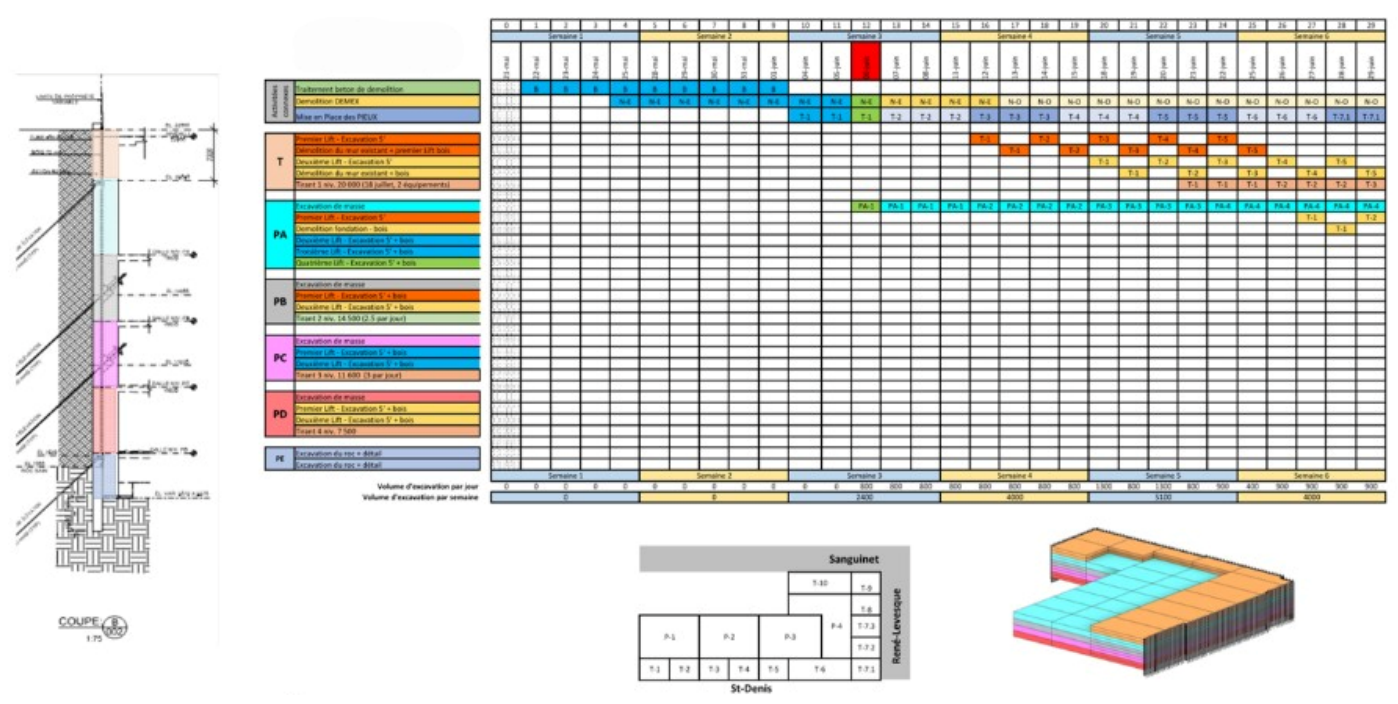

Figure 3: Partial view of the takt-time planning of the demolition, together with the retaining wall and the excavation

The takt-time plan allowed for some schedule optimization, but it was still too long and did not meet the requirements of the client. The project team explored possibilities for offsite construction of some of the systems, but the design was too advanced to be able to accommodate such a change in the approach.

\section{D simulations}

As a subsequent phase, scenarios aiming at the deconstruction and demolition optimisation were explored through 4D simulations. Construction site logistics including the neighbouring streets, and traffic simulations during the demolition were also examined. Despite the optimizations, the overall construction schedule was too long and unacceptable by the client.

\section{Integrated BIM and Lean approach}

The multidisciplinary construction (and deconstruction) team had an 'Aha-moment' when they started using the integrated communication artefact based on Unity, composed of 4D-BIM simulation connected to the takt-time plan. The deconstruction process now could be truly seen in its spatial-temporal relation to the already existing new buildings (constructed during the Phase- 1 of the project) and to the excavating and construction activities to come. Instead of separating the demolition from the excavation and the construction, due to the high level of risk, especially for the Phase-1 buildings which continued to be in operation, the construction team now could configure alternative scenarios including excavation equipment, access roads, waste removal, etc. and evaluate them from time, cost, safety and public comfort perspectives.

The collaboration between the project teams was invigorated as each stakeholder could better understand the challenges of the others and work for the schedule optimization. Precise 4D simulations were used for the evaluation of the scenarios, including for communication with the client (Figures 4 and 5).

The deconstruction and demolition timelines could now overlap with the excavation and retaining wall construction. Two months were subtracted from the overall project 
timeline and the client's expectations were met. This allowed the design-builder to win the contract.

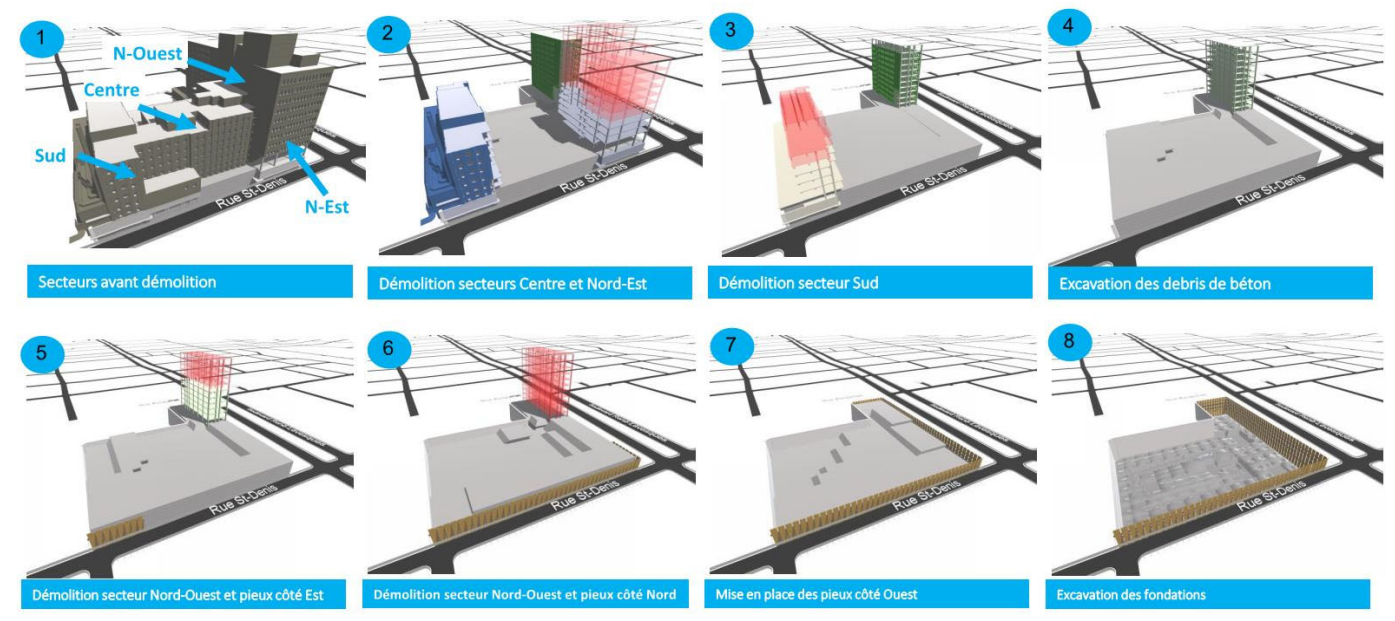

Figure 4: Integrated sequencing of the demolition, supporting walls creation and beginning of the excavation (print-screens of the 4D simulation)

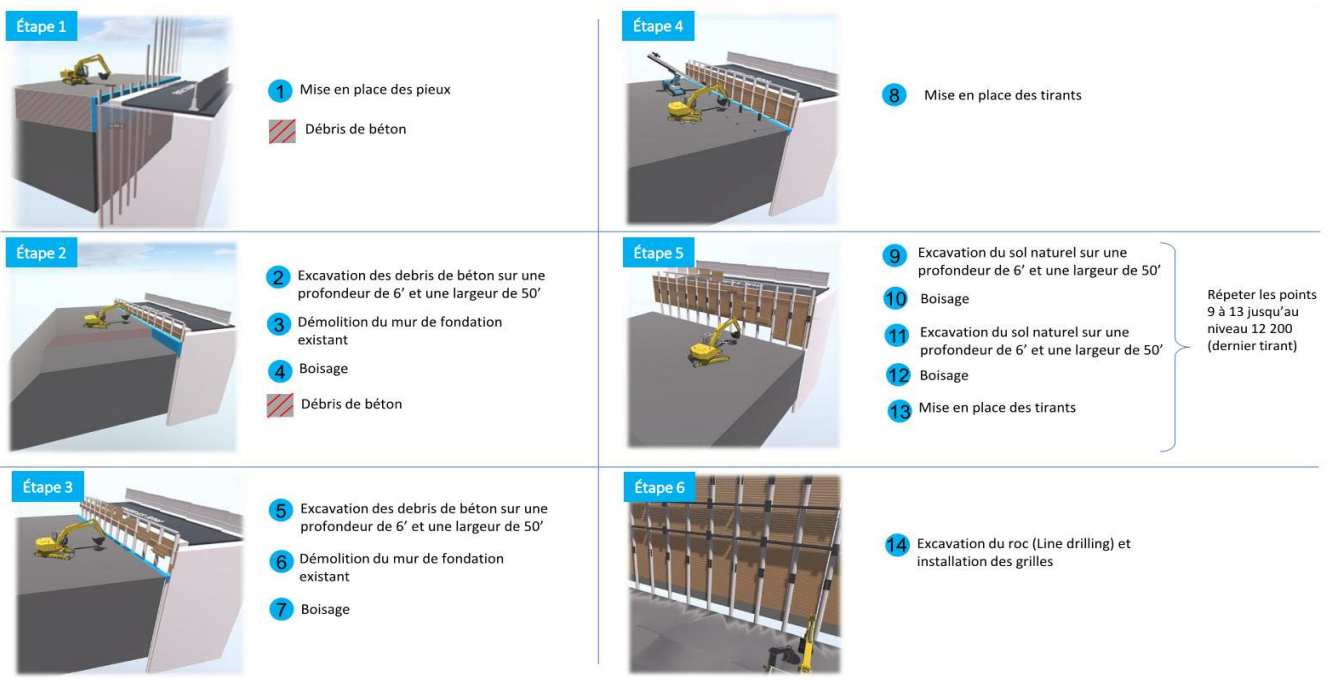

Figure 5: Animation explaining the process of shoring (Screen shots of the detailed 4D simulation of the foundations construction, linked to the takt-time plan)

\section{Progress Monitoring on an Integrated Digital Platform}

Even if the schedule was shortened enough to meet the client's expectations, the risk not to be able to follow this aggressive planning, which had become a contractual obligation, was quite high. It was crucial to be able to monitor the progress daily and to take immediate corrective action in case of deviation.

The use of production control charts (Figure 6) was an important tool for scheduling, progress tracking and communication. The chart was used to replace the classic Gantt format of the 3 weeks look ahead schedule. These charts where easily adopted by the all the stakeholders, including the client and the designers. Also, this tool was extensively 
used even by the subcontractor's crews. We observed many crew members with the printed latest version of the chart discussing field operations.

Additionally, we automatized the production of these charts, they become an output of the integrated digital platform created for the project. Therefore, any change done in the schedule was quickly ready to be published. The stakeholders (including the client) asked for the formal replacement of the classic Gantt report for this "new" production control chart.

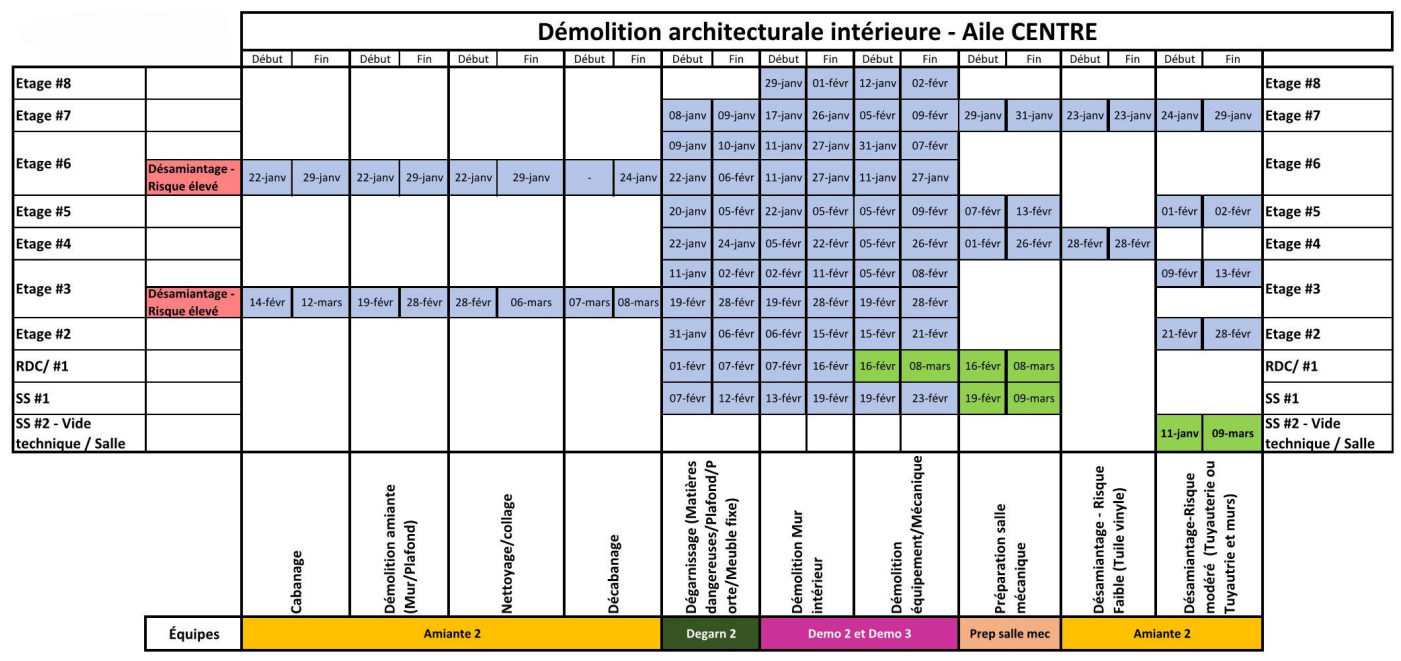

Figure 6: Production control chart used during the demolition stage

Other than the routine daily and weekly planning meetings, two other measures were implemented in order to be able to meet the contractual milestones: (1) laser scanning was used to monitor the daily productivity of demolition and excavation; (2) an integrated digital platform for planning, scheduling and progress tracking was created so that the information can be input, accessed and processed by each user in the best way (in the easiest format, software and device) suitable for him (Figure 7).

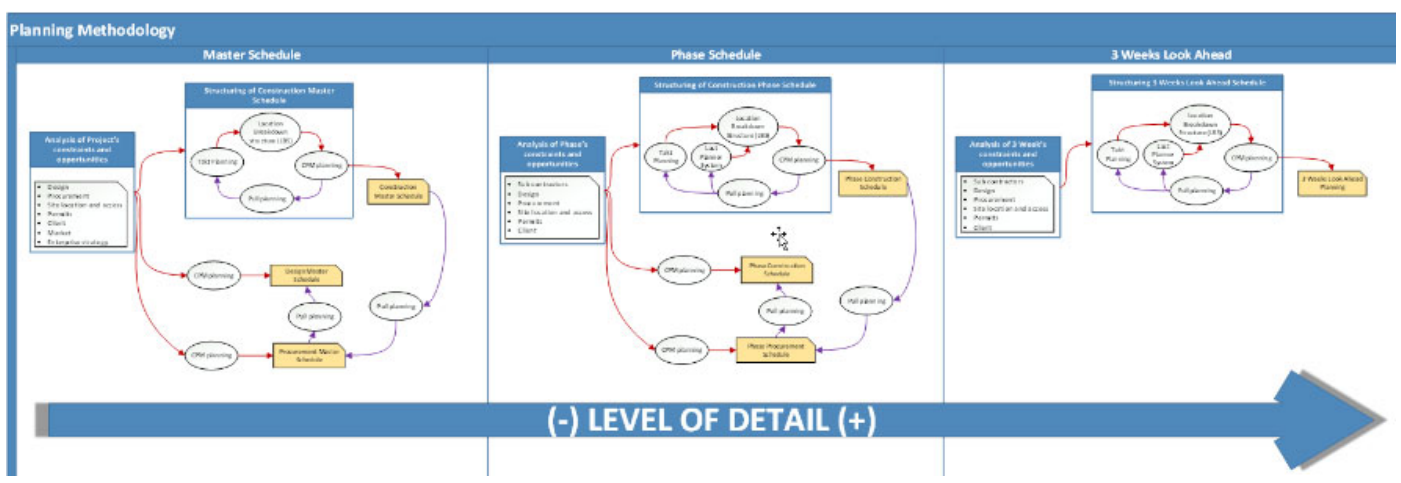

Figure 7: General scheme of the integrated 3-level planning methodology linking master schedule, work sequencing and progress monitoring of the work on site

The integrated digital platform assures semi-automated data flow between Primavera (P6) software (contractual requirement of client), MS Project (usual planning software of designers and trades), Excel (used for takt-time planning and for ACP), Revit (BIM 
model), BIM 360 Field (mobile application for progress tracking), and UniPOM (Unitybased Virtual Reality visualization platform developed in-house by the construction company). It has three connected flow loops (inspired by the Last Planner ${ }^{\circledR}$ System): (1) for the Master Schedule; (2) for the Phases Schedule; and (3) for the 3-weeks LookAhead Schedule. Different project participants interact with each of the 3 levels, but the information flows from one to the other so that all of them are up-to date and represent the current state of the planning and of the progress on-site.

\section{EVALUATION OF THE ARTEFACT}

The evaluation of the artefact can be seen in a tri-fold way: appreciation of the project team, impact on the project timeline, re-use in future projects.

Appreciation of the project team: The project team found the integrated digital Lean development extremely useful and, during interviews, discussed its positive effect on the planning activities. The superintendent, the foremen, and the trades were using the integrated spatial-temporal and takt-time representations for decision making support and for reference during the execution of the works.

An experiment (similar to Brioso et al. 2017) was done at the beginning of the project, testing the appreciation of 3 different representations of the schedule: (1) Gantt Chart, (2) Flowline, and (3) Takt-time plan with 3D color-coded representation of the activities. The sheets with the third representation were kept by the meeting participants (while the others had remained on the table at the end of the meeting), showing clearly that they were preferred to the other two communication formats.

Impact on the project timeline: The use of the integrated digital BIM/VDC/Lean platform brought a 2 months reduction of the timeline of the project, which was crucial for winning the contract. This can be interpreted as a direct proof for the positive evaluation of the artefact.

Two years after the beginning of the project and 7 months before its contractual end, the project is on-schedule, thus defying the bad statistics of mega-projects.

Re-use in future projects: The integrated 3-levels digital loop platform developed for this project was generalized and adopted as major innovation scheduling practice in the whole company. More than 20 projects are successfully using it now across the country. Other mega-projects are approached with it, aiming at schedule optimization and risk reduction.

\section{DISCUSSION}

The developed digital artefact has two aspects - one is the integrated temporal-spatial representation of all construction activities considering the initial deconstruction and demolition as integral part of the project; and the second is its generalization to an integrated 3-levels loop digital platform assuring semi-automatic data flow between various formats, devices and stakeholders.

In our opinion, the latter is a partial demonstration of the 'Simple Framework for Project Delivery' (Fischer et al. 2014), as it contributes to the integration of the information, process knowledge and organization in the context of the described megahospital project. The integration is enabled by Virtual Design \& Construction, which is considered one of the Lean strategies (Rischmoller et al. 2018). As a result, the use of the artefact at the various levels of project planning and control produces a high performance 
outcome (namely, 2 months shortening of the overall project schedule, winning the bidding competition, and staying on-schedule).

The integration of processes and teams is crucial for the success of a mega project. This contributes to the creation of a Lean Culture on the construction site, where working together in trust and respect (with designers, trades, and the client) can be supported and catalysed by the use of an integrated BIM/VDC/Lean platform. The BIM/VDC Team (Innovation Team) plays an important and trusted role in this process, both in planning of the project, and in the development of digital integrative platforms fostering collaboration.

\section{CONCLUSION}

This research is the first part of a series of papers on BIM/VDC and Lean interactions that mark the innovation strategy of a large construction and design-builder's company. The presented mega-hospital project was extremely prolific for BIM/VDC/Lean innovations aiming at the integration of the supply chain in construction, and increasing the productivity and the quality of the projects.

This paper focuses on the first stage of an integrated digital platform for project planning, scheduling and control, based on BIM/VDC and Lean Construction strategies, and including 4D simulations and project progress monitoring visual communication accessible on an integrated platform. Another paper will discuss in more detail the theoretical bases and the implementation of this artefact across teams, stakeholders, platforms and devices.

Besides the value of this work for practitioners, we consider that the integrated 3levels loop digital platform assuring data flow between the various stakeholders provides theoretical framework with scientific value, as it represents a structure for integrated planning, scheduling and project control.

In future, the artefact can surely be improved and adapted for the specificities of the different projects. It is possible, for example, that civil infrastructure projects need simplified workflow, or might better benefit from a different schedule representation. The maturity level of the stakeholders, concerning project planning and scheduling, may be a reason for adaptation of the artefact, in the context of future projects.

\section{REFERENCES}

Akbarnezhad, A., Ong, K.C.G., and Chandra, L.R. (2014). "Economic and environmental assessment of deconstruction strategies using building information modeling." Automation in Construction, 37, 131-144.

Akinade, O.O., Oyedele, L. O., Omoteso, K., Ajayi, S. O., Bilal, M., Owolabi, H.A., Alaka, H.A., Ayris, L., and Looney, J.H. (2017). "BIM-based deconstruction tool: Towards essential functionalities." IJSBE, 6(1), 260-271.

Ballard, G. (2000). "Lean project delivery system." Working paper 8, Lean Construction Institute, also at http://p2sl.berkeley.edu/wp-content/uploads/2016/03/W008-Ballard2000-Lean-Project-Delivery-System-LPDS-LCI-White-Paper-8-rev-1.pdf

Bernardes M.M.S. (2003). Planejamento e controle da produção para empresas de construção civil. (Production planning and control for construction companies), Rio de Janeiro, Brasil: LTC.

Boston Consulting Group (2018). Boosting productivity in construction with Digital and Lean. $\quad$ www.bcg.com/fr-ca/publications/2018/boosting-productivity-constructiondigital-lean.aspx 
Brioso, X., Murguia, D., and Urbina, A. (2017). "Comparing three scheduling methods using BIM models in the Last Planner System." Organization, Technology and Management in Construction: an International Journal, 9(1), 1604-1614.

Elmaraghy, A., Voordijk, H., and Marzouk, M. (2018). “An Exploration of BIM and Lean Interaction in Optimizing Demolition Projects" Proc. IGLC-26, Chennai, India, 112122.

Fischer, M., Reed, D., Khanzode, D.A., and Ashcraft, H.W. (2014). "A Simple Framework for Integrated Project Delivery.” Proc. IGLC-22, Oslo, Norway, 13191330.

Frandson, A., Berghede, K., and Tommelein, I.D. (2014). "Takt-Time Planning and the Last Planner." Proc. IGLC-22, Oslo, Norway, 571-580.

Ge, X. J., Livesey, P., Wang, J., Huang, S., He, X., and Zhang, C. (2017). "Deconstruction waste management through 3D reconstruction and BIM: a case study." Visualization in Engineering, 5(1), 13.

Ghio, V., Valle, E., and Rischmoller, L. (1997). "Preplanning: A rewarding experience." Proceedings of IGLC-5, Gold Coast, Australia, 115-120.

Hevner, A., and Chatterjee, S. (2010). Design Research in Information Systems. Integrated Series in Information Systems, Springer US, Boston, MA.

Iordanova, I., Valdivesio, F., and Filion, C. (2019). BIM and Lean for Project Planning and Control. CSCE, Laval, Canada.

Kenley, R. and Seppänen O. (2009). "Location-based management of construction projects: part of a new typology for project scheduling methodologies." WSC 2009, IEEE, pp. 2563-2570.

Melzner, J. (2019). "BIM-based Takt-Time Planning and Takt Control: Requirements for Digital Construction Process Management." 36th ISARC, Canada.

Paul, N. and Borrmann, A. (2009). "Geometrical and topological approaches in building information modelling." ITCon, 14(46): 705-723.

Rischmoller, L., Reed, D., Khanzode, A., and Fischer, M. (2018). "Integration Enabled by Virtual Design and Construction as a Lean Implementation Strategy." Proc. IGLC26, Chennai, India, 240-249.

Sacks, R. (2018). Building lean, building BIM: improving construction the Tidhar way. Routledge, Abingdon, Oxon; New York, NY.

Sacks, R., Koskela, L., Dave, B.A., and Owen, R. (2010a). "Interaction of Lean and Building Information Modeling in Construction." Journal of Construction Engineering and Management, 136(9), 968-980.

Sacks, R., Radosavljevic, M., and Barak, R. (2010b). "Requirements for building information modeling based lean production management systems for construction." Automation in Construction, 19(5), 641-655.

Schultmann, F. and Rentz, O. (2002). "Scheduling of deconstruction projects under resource constraints." Construction Management and Economics, 20(5), 391-401.

Tahrani, S., Poirier, A, and Forgues, D. (2015). "Structuring the adoption and implementation of BIM and integrated approaches to project delivery across the Canadian AECO industry: Key drivers from abroad." Proc. 5th International and 11th Construction Specialty Conference (ICSC'15), Vancouver, Canada, 8-10 June, 59-69.

World Economic Forum (2016). "Shaping the Future of Construction - A Breakthrough in Mindset and Technology." www3.weforum.org/docs/WEF_Shaping_the_Future_of_Construction_full_report .pdf 